\title{
Breast cancer screening among women with intellectual disability
}

Dr. PD Christine Bouchardy is the head of the Geneva cancer registry, member of the executive committee of the Swiss Cancer League and a specialist in cancer epidemiology and public health

Breast cancer is the most common cancer among women. Despite treatment progress this cancer remains the first cause of death in middle-aged women. Today it is internationally recognised that mammography screening decreases mortality from breast cancer for women aged 50 to 69 years. In western societies where the risk is especially high, every woman of this age group should have access to high quality mammography screening every two years.

The number of persons with intellectual disability (ID) is growing mainly because of the rising life expectancy of patients with ID (Hogg et al. 2000). Adults with ID can now expect to reach middle- and even old age. We estimate that over $1 \%$ of the European population has intellectual disability at different degrees of severity.

With an exception for women with Down's syndrome who apparently are at lower risk of breast cancer, women with ID share at least a similar risk of breast cancer with other women (Satgé \& Sasco 2002; Patja et al. 2001). These women could therefore also expect similar benefits of mammography screening, such as early stage at diagnosis, less mutilating surgery, less chemotherapy, and increased chance of cure. Lack of access to mammography screening among this growing population will result in an excess of preventable breast cancer mortality. In addition, it will cause individual damage when metastases occur. These women will also experience similar adverse effects of mammography, such as anxiety and unnecessary investigations linked to false positive results.

Several studies have clearly demonstrated that women with ID have lower access to cervical and breast cancer screenings (Pearson et al. 1998; Piachaud \& Rohde 1998). Even in the context of population-based organised programmes, women with ID are less often invited to screening (Davies \& Duff 2001).
In this edition, Sullivan et al. (2004), investigate reasons why women with ID do not use mammography screening. The study was performed among social trainers in charge of women with mild to severe ID in Australian institutions. The main reasons for under-use of mammography screening according to the carers were lack of information on screening, belief that women could not provide informed consent and had higher anxiety and physical limitations to perform the test. The authors conclude that mammography screening is too arduous for these women and propose clinical examination as an alternative. However, a large fraction of this study concerned women with severe ID and their conclusions do not cover all women with ID.

Women with mild or moderate ID should benefit from breast cancer screening without discrimination, just like the general population. Only the severity of intellectual degradation and practical obstacles should modulate the indication with a case to case approach. We can understand that mammography screening is not indicated for women with severe ID for whom daily life is dominated by their handicap and who, in case of breast cancer diagnosis, could not undergo optimal treatment.

Informed consent cannot be obtained in the optimal way since these women cannot weigh the advantages and adverse effects of the test and make the best choice themselves. It is unacceptable that no information on screening mammography will be given to these women simply because they have mental disability. The procedure of mammography screening can be explained in simplified terms and by taking time to answer questions and minimize anxiety linked to the procedure. Many patients with ID are able to understand important elements of an informed consent (Carpenter 1999) and have the right to choose.

Soz.- Präventivmed. 49 (2004) 361-362 
We agree that screening strategy needs to be adapted to the patient's health status, but must offer the best chance to detect curable cancer. As clinical examination also needs informed consent and has no proven effect to decrease breast cancer mortality, it is not a good alternative to mammography screening.

Only concerted efforts between healthcare professionals will result in better quality health services for this particular group of people, their carers and family.

There is much room for improvements to reduce inequalities in access to screening mammography. Mammography service providers should examine why numerous women with ID are excluded from their databases and offer them specific support and information.

In addition, the role of the general practitioner concerning health promotion and routine screening for these patients must be reinforced. General practitioners are not prepared to deal with the complex combination of physical and psychiatric problems of these patients. They often feel that they lack necessary skills and knowledge to provide health promotion and screening services to this vulnerable group (Kerr et al. 1996).

Community teams in charge of patients with ID play a key role in the support, education and information on health promotion. However, they are often not informed on screening possibilities, its constraints and benefits. Training care providers is therefore also an important challenge. Despite the increasing knowledge on the needs of adults with intellectual disability we need more transparency and research to quantify health inequalities and their reasons. This vulnerable and marginalised population constitutes a growing public health problem. They need targeted programs of medical care and prevention to minimize the impact of their ID and to improve their quality of life.

Christine Bouchardy Magnin

\section{References}

Carpenter WT (1999). The challenge to psychiatry as society's agent for mental illness treatment and research. Am J Psychiatry 156: 1307-10.

Davies N, Duff M (2001). Breast cancer screening for older women with intellectual disability living in community group homes. J Intellect Disabil Res 45: 253-7.

Hogg, J (2001). Healthy ageing - adults with intellectual disabilities: ageing and social policy. J Appl Res Intellect Disabil 14: 229-55.

Kerr M, Dunstan F, Thapar A (1996). Attitudes of general practitioners to caring for people with learning disability. Br J Gen Pract 46: 92-4.
Patja K, Eero P, Livanainen (2001). Cancer incidence among people with intellectual disability. J Intellect Disabil Res 45: 300-7.

Pearson V, Davis C, Ruoff C, et al. (1998). Only one quarter of women with learning disability in Exeter have cervical screening. BMJ 316: 1979.

Piachoud J, Rohde J (1998). Screening for breast cancer is necessary in patients with learning disability. BMJ 316: 1979-80.

Satgé D, Sasco AJ (2002). Breast screening guidelines should be adapted in Down's syndrome. BMJ 324: 1155

Sullivan SG, Slack-Smith LM, Hussain R (2004). Understanding the use of breast cancer screening servies by women with intellectual disabilities. Soz Praventiv Med 49: 398-405

\section{Address for correspondence \\ PD Dr. Christine Bouchardy Magnin Registre genevois des tumeurs Institut de médecine sociale et préventive Faculté de médecine Université de Genève Boulevard de la Cluse 55 CH-1205 Genève e-mail: christine.bouchardymagnin@imsp. unige.ch}

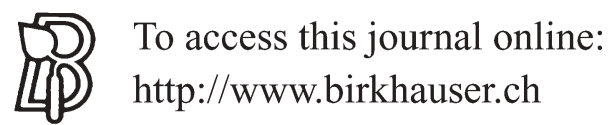

